\title{
Oil prices and unemployment in the UK before and after the crisis: A Bayesian VAR approach. A note.
}

\author{
Juan Carlos Cuestas* \\ Department of Economics and IEI \\ Jaume I University \\ Department of Economics and Finance \\ Tallinn University of Technology \\ Javier Ordóñez \\ Department of Economics and IEI \\ Jaume I University
}

\begin{abstract}
The aim of this paper is to analyse the role of oil price movements in the evolution of unemployment in the UK, accounting for asymmetric effects. Distinguishing between positive and negative innovations in oil prices allows us to provide policy insights. Estimating Bayesian SVARs, we find that the relationship between oil prices and unemployment in the UK differs before and after the beginning of the Great Recession. We also find that negative oil price innovations have contributed positively to preventing further rises in unemployment after the start of the crisis in 2008.
\end{abstract}

Key words: oil prices; unemployment; asymmetries; Bayesian VAR.

JEL code: $\quad$ C22, F15.

*Corresponding author; email: cuestasjuancarlos@gmail.com.

Acknowledgements: The authors gratefully acknowledge the financial support from the research grant ECO2017-83255-C3-3-P 'Programa Estatal de Fomento de la Investigación, Científica y Técnica de Excelencia, Subprograma Estatal de Generación de Conocimiento, Ministerio de Economía, Industria y Competitividad (MINEIC), Gobierno de España, 2018-2020'. Juan Carlos Cuestas also acknowledges the ECO201785503-R project by the MINEIC and Javier Ordóñez gratefully acknowledges financial support from 'Universitat Jaume I' grant no UJI-B2017-33 and the 'Generalitat Valenciana' PROMETEOII/201/053 research grant. 


\section{Introduction}

Many countries have suffered the consequences of the 2008-2014 Great Recession, which started in the US after the Lehman Brothers bankruptcy, with most advanced economies experiencing a rise in public debt, higher unemployment and a steep fall in GDP.

The UK is no exception; however, the consequences in terms of job losses have been less damaging than in Southern Europe. As Figure 1 shows, on the one hand, the unemployment rate jumped nearly three percentage points between 2008 and 2009. However, compared with other European countries, this increase in unemployment is very small.

On the other hand, there have been conflicting opinions about oil price movements and their effects on the dynamics of economic variables. As can be seen in Figure 1, oil prices experienced a sustained increase during 2001-2008, with a sudden drop between 2008 and 2009 due to the fall in world demand.

Figure 1: Unemployment and oil price, 2000Q1-2014Q4

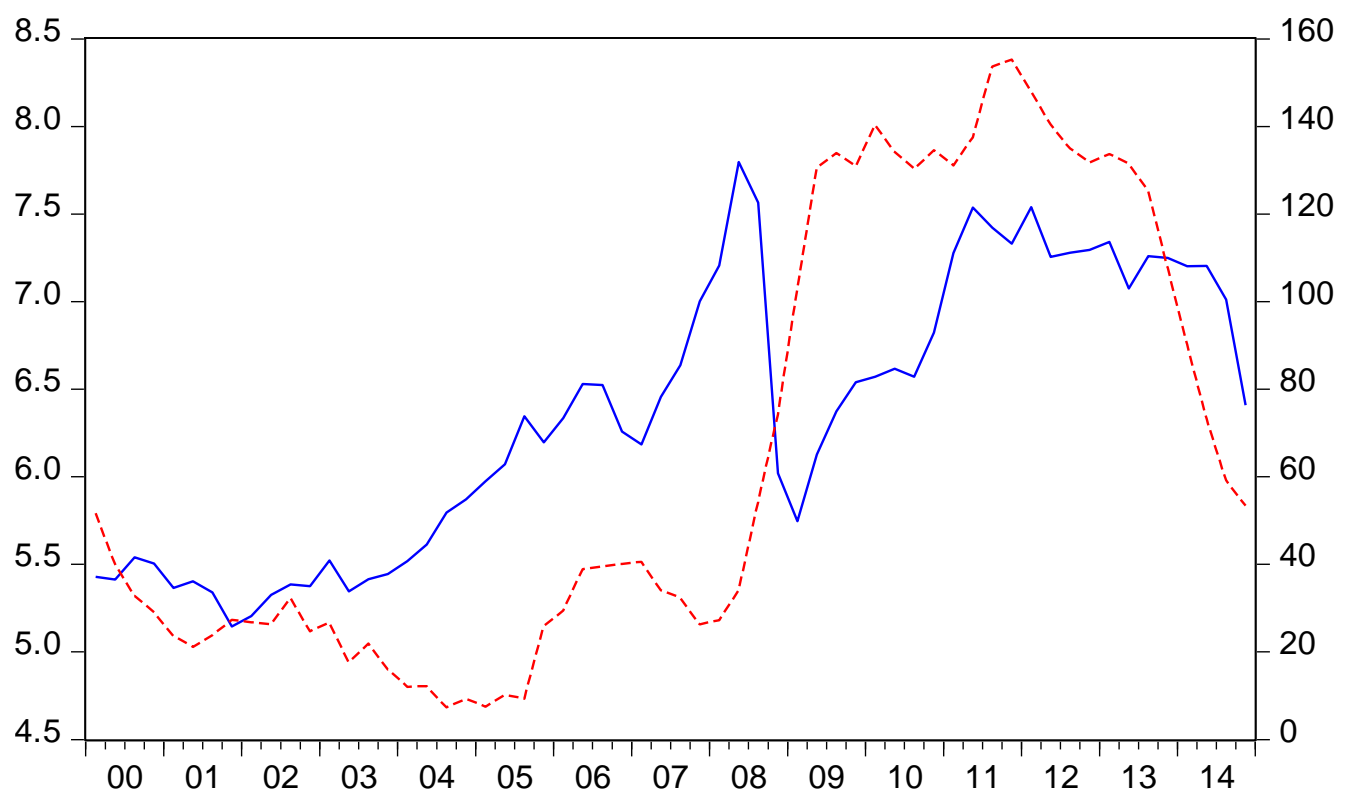

Note: The dashed line is the unemployment rate, left axis; and the solid line is the real oil price in US dollars, right axis. See section 3 for the definition of the variables. 
From Figure 1, we can also observe that there seems to be a co-movement between oil prices and unemployment, in particular after 2005 and before the eruption of the crisis in 2008. After this date, however, the relationship is less clear; if anything, it appears that unemployment leads oil price movements.

Although there is extensive literature on the impact of oil price shocks on GDP — see for instance Cunado and Perez de Gracia (2003), Jiménez-Rodríguez (2009) and Jiménez-Rodríguez and Sánchez (2005), among many others - the oil price-unemployment nexus has received comparatively less attention within the academic literature. Cunado and Perez de Gracia (2003) highlight the importance of asymmetric effects on economic growth; however, they find that the signs of the effect are country dependent. In their two contributions, Jiménez-Rodríguez (2009) and Jiménez-Rodríguez and Sánchez (2005) find that in most cases only positive innovations have an effect on growth, although again there are some differences depending on the countries considered. Andreopoulos (2009), Cuestas (2016) and Gil-Alana (2003, 2006) find that oil price shocks tend to have negative effects on employment and that there is evidence that the effects of positive and negative shocks may differ in magnitude. These results are in line with the theoretical foundations of Hamilton $(1983,1988)$ and Carruth et al. (1998), according to which an oil price shock can be identified as an aggregate supply shock, in particular in net oil importing countries such as the UK. However, the UK also produces some oil and hence a negative oil price shock can affect revenues from its production.

The theoretical connection between unemployment and commodity supplies appears in Hamilton's (1988) seminal contribution, where he argues that unemployment reacts to the business cycle, which in turn is amplified by primary commodity shocks. Thus, according to Hamilton's (1988) model, the link between unemployment and oil prices comes from the fact that oil prices are the main source of business fluctuations. Later, the model of Carruth et al. (1998) uses the Shapiro and Stiglitz (1984) efficiency wage model such that the equation for wages is written as follows:

$$
\log w=\log b+e+\frac{e \cdot d}{[1-a(U)](1-d)},
$$

where $w$ is wage, $b$ is unemployment benefits, $e$ is the amount of effort put in at work by workers, $d$ is the probability of not putting in any effort, $U$ is the rate of unemployment, and $a(U)$ is a 
negative function of unemployment which refers to the probability of finding a job. Hence, on the one hand, workers try to maximise the difference between wages and level of effort, bearing in mind that the smaller $e$, the higher the probability of getting fired. On the other hand, firms should pay enough to motivate workers and increase their $e$. With this set up, Carruth et al. (1998) find that the unemployment rate equation can be written as:

$$
U^{*}=U^{*}\left(r, p_{o}, b(\mu), e, d\right)
$$

where wages, $w$, rental rate, $r$, and the oil price, $p_{o}$ determine marginal costs $\mu=c\left(w, e, p_{o}\right)$, with $\frac{\partial U}{\partial r}>0$ and $\frac{\partial U}{\partial p_{o}}>0$. Equation (2) implies that as oil prices increase, firms are forced to fire workers to reduce production costs and return to profit maximising conditions.

Related to this point, Gil-Alana and Henry (2003), analysing the period 1966Q1-1997Q4, find that there is a positive relationship between the UK unemployment and oil prices. More recently, Katircioglu et al. (2015) also find that oil price increases negatively affect GDP, consumer prices and unemployment. However, they highlight that in some cases the effect on unemployment is not significant. Contrary to these results, Frias-Pinedo et al. (2017) find that, in Spain, oil price innovations have a positive impact on unemployment and a negative impact on GDP.

In this paper, using quarterly observations and Bayesian structural vector autoregressive (SVAR) models, we analyse the effect of oil price innovations on unemployment in the UK, for the period 2000Q1-2014Q4, for the pre-crisis period 2000Q1-2007Q4 and the crisis period 2008Q12014Q4. The use of Bayesian techniques offers an advantage over frequentist econometrics in that it enables prior information to be included in the modelling, enriching the overall information set used for the estimations. In addition, according to Sims (1988) the existence of unit roots in the data does not affect the inference. Following Jiménez-Rodríguez and Sánchez (2005) we also distinguish between positive and negative oil price innovations, i.e. asymmetric effects of oil prices on unemployment, and we control for other fundamentals such as GDP, discretionary public deficit and interest rates. We thus aim to analyse a more recent period than in Jiménez-Rodríguez and Sánchez (2005), using Bayesian methods and focusing explicitly on the pre- and post-crisis periods. 
The remainder of the paper is organised as follows. The next section summarises the methods used in this empirical application, while sections 3 and 4 present the results and conclusions, respectively.

\section{Methodology}

In this paper, we estimate Bayesian SVAR models in order to analyse the oil priceunemployment rate nexus. Bayesian methods differ from frequentist econometrics in that they combine prior information along with the likelihood function to obtain a posterior distribution for the parameters of interest, using the Bayes theorem,

$$
\pi(\partial \mid Y)=\frac{f(Y \mid \partial) \pi(\partial)}{f(Y)}
$$

where $\partial$ refers to a set of parameters which we are interested in estimating, $\pi(\partial \mid Y)$ is the posterior distribution of these parameters conditional to the dataset $Y, f(Y \mid \partial)$ refers to the likelihood density functions, $\pi(\partial)$ is a set of priors with a probability distribution and $f(Y)$ is the data density.

There are a number of different probabilistic distributions for priors used in time series, and SVARs in particular. The Minnesota prior of Litterman (1986) is probably the most popular one, as it also deals with the issue of unit roots in the data. However, this prior imposes prior knowledge of the residual variance-covariance matrix. Hence the variance of the coefficients of the $\mathrm{VAR}, \delta_{i j}$, are:

$$
\begin{gathered}
\sigma_{\delta_{i i}}^{2}=\left(\frac{\lambda_{1}}{l^{\lambda_{3}}}\right)^{2} \\
\sigma_{\delta_{i j}}^{2}=\left(\frac{\sigma_{i}^{2}}{\sigma_{j}^{2}}\right)\left(\frac{\lambda_{1} \lambda_{2}}{l^{\lambda_{3}}}\right)
\end{gathered}
$$

where $\sigma_{i}^{2}$ and $\sigma_{j}^{2}$ refer to the OLS residual variance of the models of the $i$ th and $j$ th variables, $l$ is the lag, $\lambda_{1}$ is the the variance of the lag, $\lambda_{2}$ is the cross-variable specific variance parameter, and $\lambda_{3}$ is related to the convergence towards 0 for the parameters of lag 2 onwards. 
In this paper we relax some of the assumptions of the Minnesota prior and use instead the independent normal-Wishart prior, which does not impose prior knowledge of the residual variance-covariance matrix and that there is no dependence between the residual and coefficient variance. We have set the following values for these parameters, as they are standard in the literature; $\lambda_{1}=0.1, \lambda_{2}=0.5$ and $\lambda_{3}=1$ (Dieppe et al. 2016)

To identify the shocks within the SVAR models we use triangular factorisation à la Cholesky with 1-unit shocks. Hence, if we apply the same shock in the two subsamples analysed, the results obtained in the impulse response functions are more comparable than if we apply a standard deviation shock.

\section{Data and results}

Data for oil prices have been downloaded from the US Energy Information Administration and is the Brent Spot Price FOB (dollars per barrel). Prices have been deflated using the US harmonised consumer price index, downloaded from Eurostat. Seasonally adjusted series for unemployment rates, real GDP, government expenditure and government revenue have been downloaded from Datastream. In addition, as a control variable to control for monetary policy, we have included the central bank interest rates from the IFS of the IMF. The real GDP and real oil prices have been used in logs, $y_{t}$ and $p_{t}$ respectively, while the interest rates and unemployment rates have been divided by $100, i_{t}$, and $u_{t}$. To account for the fiscal policy, we have first removed the effect of the current GDP and previous spending/tax revenue by using the residuals of the following regressions:

$$
\begin{gathered}
g \exp _{t}=\alpha_{0}+\alpha_{1} y_{t}+\alpha_{2} g \exp _{t-1}+\varepsilon_{t}^{g \exp } \\
\operatorname{grev}_{t}=\beta_{0}+\beta_{1} y_{t}+\beta_{2} \operatorname{grev}_{t-1}+\varepsilon_{t}^{g r e v}
\end{gathered}
$$

where $g \exp _{t}$ and $\operatorname{grev}_{t}$ are, respectively, the logs of government expenditure and government revenue in real terms using the consumer price index as a deflator. The idea is to remove the effect of the automatic stabilisers (given by the GDP movements) and the autocorrelation of the 
previous year's tax revenue and expenditure. The residuals of equations (6) and (7), then, reflect the fiscal policy decisions made on top of the previous year's fiscal policy and automatic stabilisers (see for instance Blanchard and Perotti, 2002). We then obtain what we call the discretionary public deficit as $d e f_{t}=\hat{\varepsilon}_{t}^{\text {gexp }}-\hat{\varepsilon}_{t}^{\text {grev }}$. Hence, our vector of variables consists of $Y_{t}=\left(i_{t}, p_{t}, d e f_{t}, y_{t}, u_{t}\right)$. Several descriptive statistics are shown in the Appendix along with Granger causality tests for the exclusion of oil prices. ${ }^{1}$ For all variables, we have used quarterly observations for the period 2000Q1-2014Q4.

In addition, as mentioned above, we aim to distinguish between the effect of negative and positive real oil price innovations on unemployment. Hence, based on Jiménez-Rodríguez and Sánchez (2005) we obtain

$$
p_{t}^{+}=\sum_{k=1}^{t} \max \left(\Delta p_{k}, 0\right)
$$

and

$$
p_{t}^{-}=\sum_{k=1}^{t} \min \left(\Delta p_{k}, 0\right)
$$

implying a second vector of variables: $Z_{t}=\left(i_{t}, p_{t}^{+}, p_{t}^{-}, d e f_{t}, y_{t}, u_{t}\right)$.

The SVARs are estimated using 2 lags. This lag length has been selected using the Bayesian Information Criterion. The variables are ordered so as to let all shocks contemporaneously affect unemployment, hence this variable has been placed last.

Figure 2: Response of unemployment to a real oil price innovation (vector $X_{t}$ )

\footnotetext{
${ }^{1}$ As requested by an anonymous referee.
} 


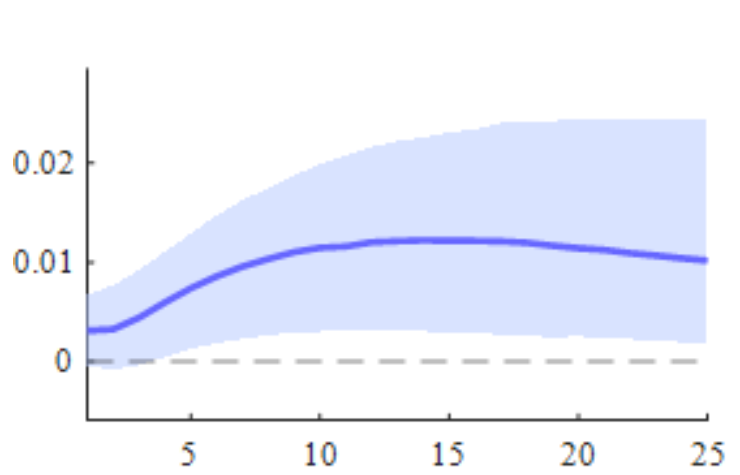

(a) Full sample

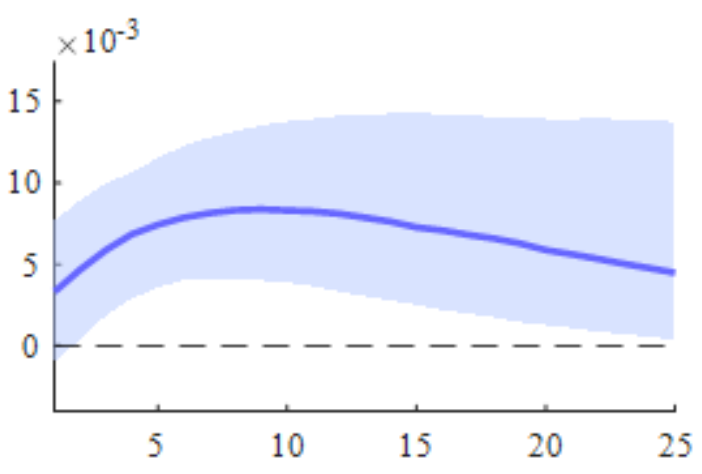

(b) 2000Q1-2007Q4 sample

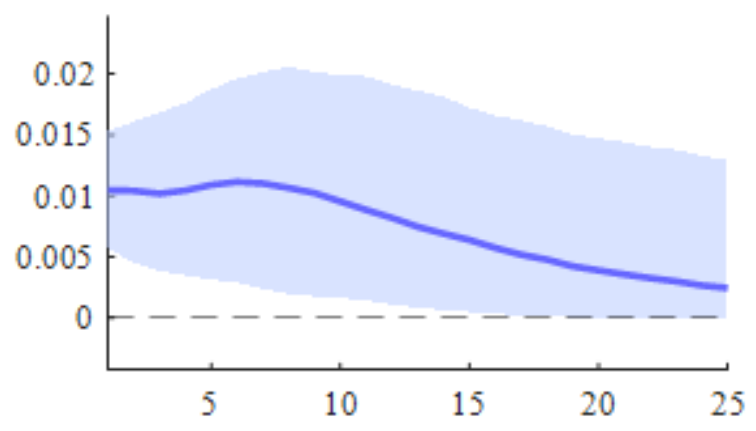

(c) $2008 \mathrm{Q} 1-2014 \mathrm{Q} 4$

Note: The dark line is the median and the shaded area is the $68 \%$ credible set. 
Figure 3: Forecast error variance decomposition for all innovations to unemployment (vector $X_{t}$ )

(1) Period 2000Q1-2014Q4

(a) $i_{t}$

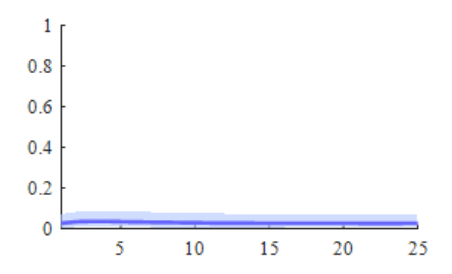

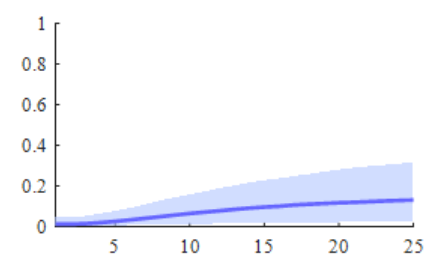

(b) $p_{t}$

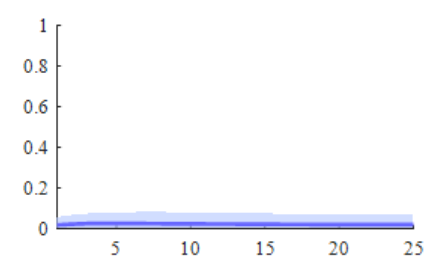

(c) $\operatorname{def}_{t}$

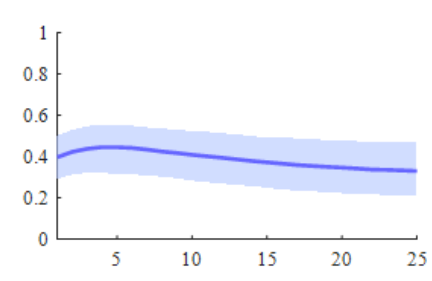

(c) $d e f_{t}$

(3) Period 2008Q1-2014Q4

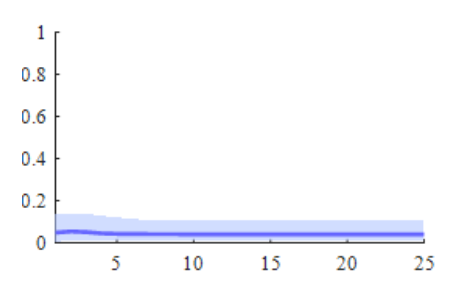

(a) $i_{t}$

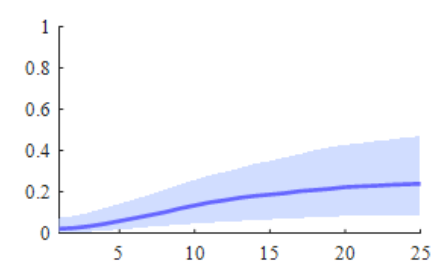

(b) $p_{t}$

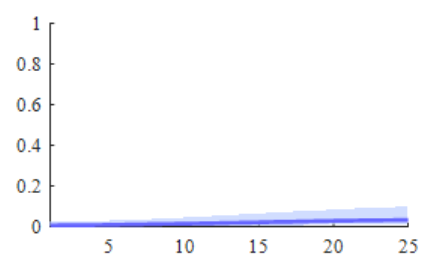

(d) $y_{t}$

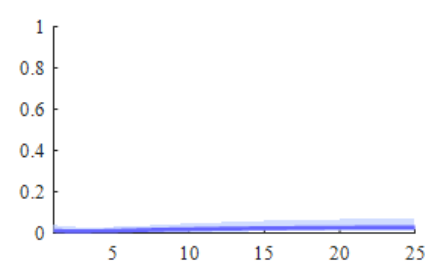

(d) $y_{t}$

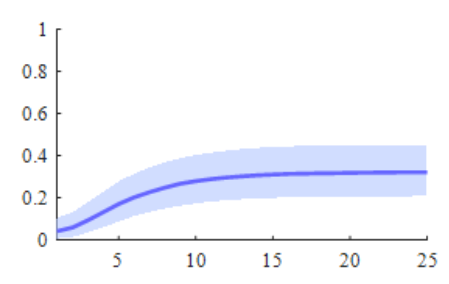

(d) $y_{t}$

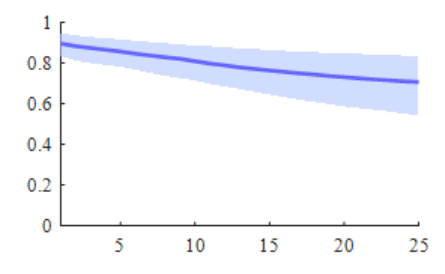

(e) $u_{t}$

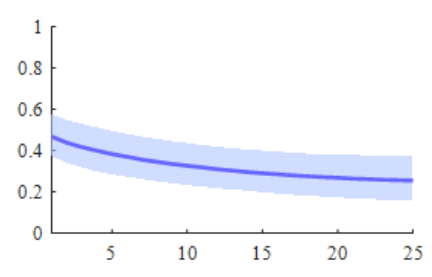

(e) $u_{t}$

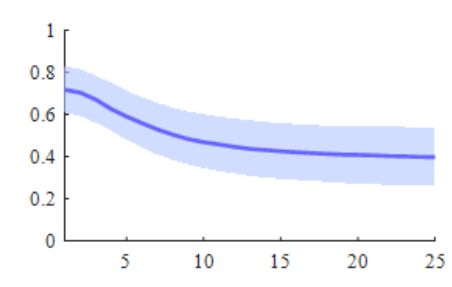

(e) $u_{t}$

Note: The dark line is the median and the shaded area is the $68 \%$ credible set. 
In Figure 2, we display the impulse response functions and the $62 \%$ credible sets for a 1-unit oil price shock on unemployment, for vector $X_{t}$. We observe that in the three periods considered, the effect is qualitatively the same, namely that a positive oil price innovation causes an increase in unemployment. However, when comparing the results for the pre-crisis period with those for the post-crisis period, we find that the oil price innovation provokes a stronger shift in the posterior distribution for the crisis period. In Figure 3, we display the forecast error variance decomposition for all innovations to unemployment. We find that the contribution of oil price shocks increases over time in the pre-crisis period, whereas it stays constant below $20 \%$ in the crisis period. Comparing to the contribution of oil price shocks to that of the other shocks, we also find that for both samples oil price shocks are the third most important contributors. However, when looking at panel (1) of Figure 3, for the full period, it appears that oil price shocks are the most important after unemployment shocks, due to the high persistence of the latter.

In Figure 4, we display the impulse response functions accounting for asymmetric effects, i.e. based on vector $Z_{t}$. We observe that for both the full and pre-crisis period, positive innovations seem to have a stronger effect in terms of the magnitude of the response of unemployment. Note that panels (b) indicate that unemployment will react in the same direction if the posterior is above the zero line. When looking at the impulse response functions for the crisis period, it appears that the effect of the positive innovations occurs only on impact, and drops off afterwards. However, when looking at Figure 4 (3) (b), it appears that the effect of negative innovations seems to multiply over time, with subsequent decreases in unemployment as time goes by.

This is corroborated by Figure 5, which displays the forecast error variance decomposition for all innovations to unemployment, vector $Z_{t}$. It appears that, before the crisis, positive shocks seem to make a greater contribution than negative innovations, whereas in the crisis period, negative innovations make the second most important contribution to the unemployment variance after unemployment shocks. This implies that, after 2008, negative oil price movements have positively contributed to keeping unemployment at comparatively low levels. 
As corroborated by the strictness of employment protection index, the UK has the most flexible labour market in Europe. ${ }^{2}$ This explains one of the main results; namely, that unemployment seems to be quite sensitive to oil price shocks.

Our results are generally in line with expectations, i.e. oil price shocks have a detrimental effect on employment. However, we find that our results are different to those of Katircioglu et al. (2015) in the sense that oil price shocks may not affect unemployment. This difference might be due to the fact that they use panel data estimations meaning that the effects of different countries in the pool may be averaged out.

Finally, our results are backed up by the recent contribution of Evgenidis (2018), who finds that the effect of shocks depends not only on the sign and size of the shock, but also on the degree of uncertainty and economic stress.

\footnotetext{
${ }^{2}$ https://stats.oecd.org/Index.aspx?.DataSetCode=EPL_OV. We thank an anonymous referee for point this out.
} 
Figure 4: Response of unemployment to oil price innovations, asymmetric effects (vector $Z_{t}$ )

(1) Period 2000Q1-2014Q4
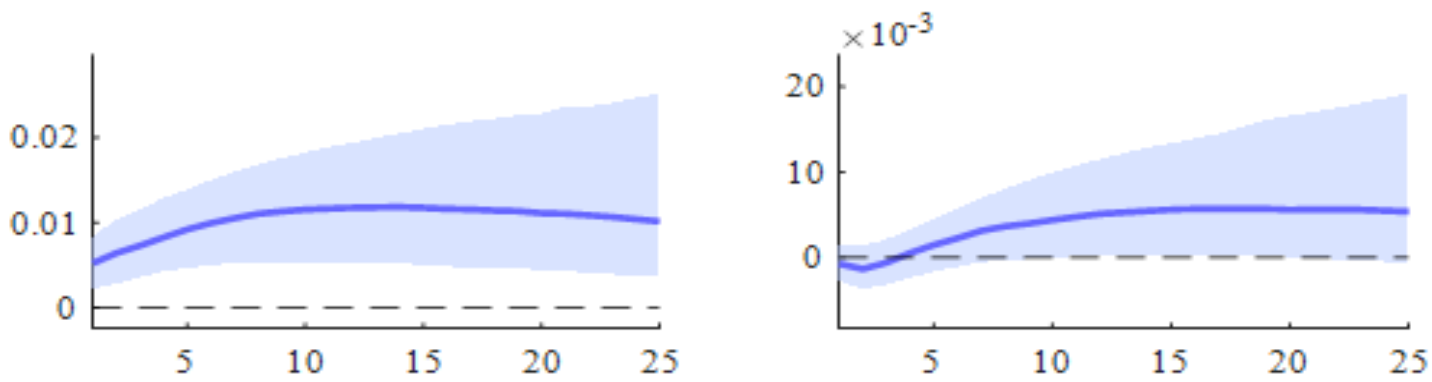

(a) $u_{t}$ response to a $p_{t}^{+}$innovation

(b) $u_{t}$ response to a $p_{t}^{-}$innovation

(2) Period 2000Q1-2007Q4
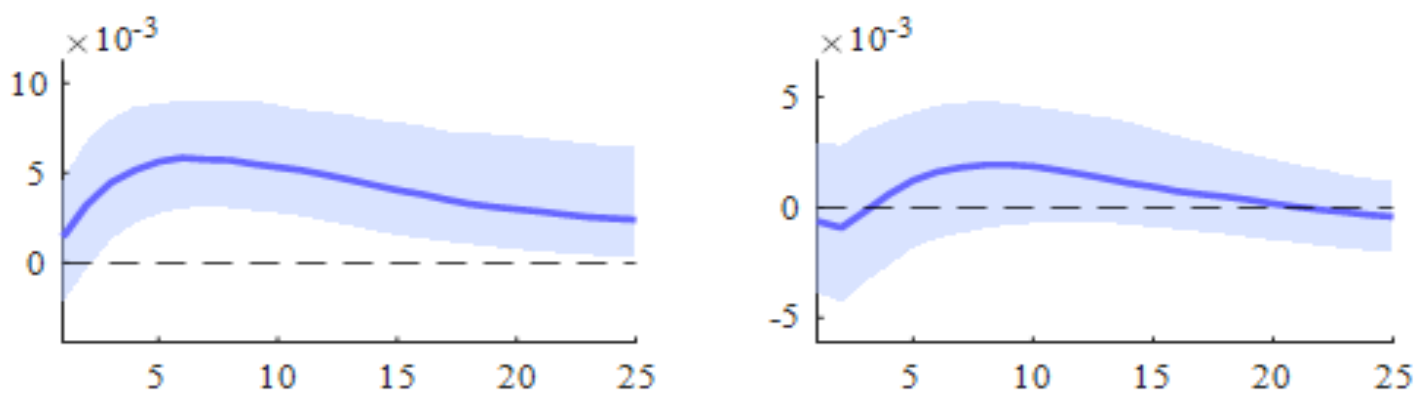

(a) $u_{t}$ response to a $p_{t}^{+}$innovation

(b) $u_{t}$ response to a $p_{t}^{-}$innovation

\section{(3) Period 2008Q1-2014Q4}

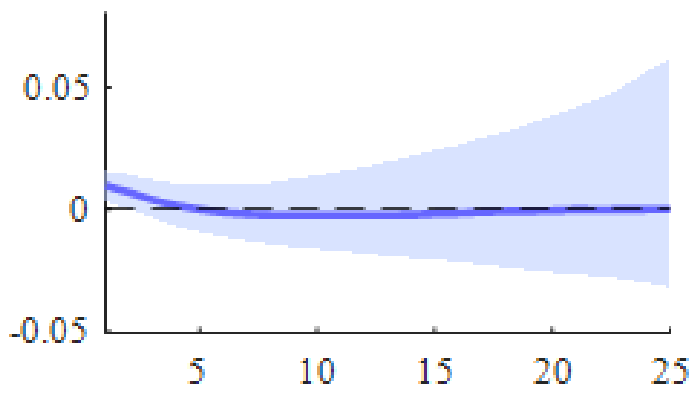

(a) $u_{t}$ response to a $p_{t}^{+}$innovation

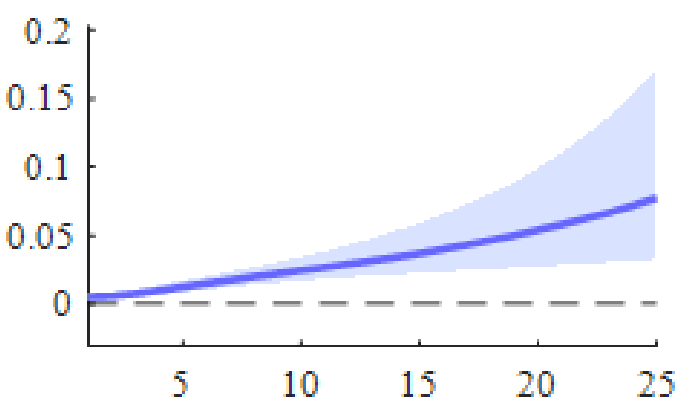

(b) $u_{t}$ response to a $p_{t}^{-}$innovation

Note: The dark line is the median and the shaded area is the $68 \%$ credible set. Note that panels (b) indicate that unemployment will react in the same direction if the posterior is above the zero line. 
Figure 5: Forecast error variance decomposition for all innovations to unemployment, asymmetric effects (vector $Z_{t}$ )

(1) Period 2000Q1-2014Q4

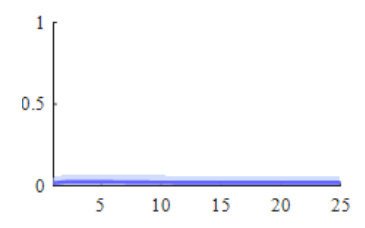

(b) $i_{t}$

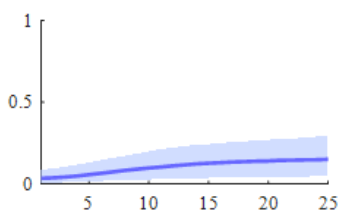

(b) $p_{t}^{+}$

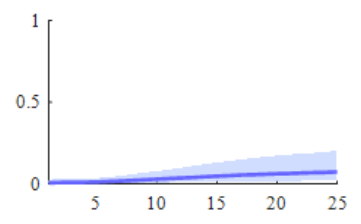

(c) $p_{t}^{-}$

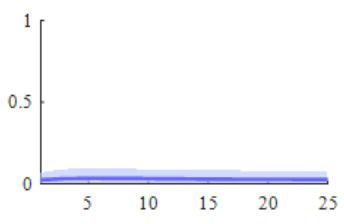

(d) $d e f_{t}$

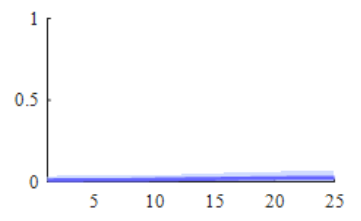

(e) $y_{t}$

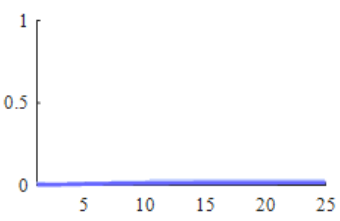

(e) $y_{t}$
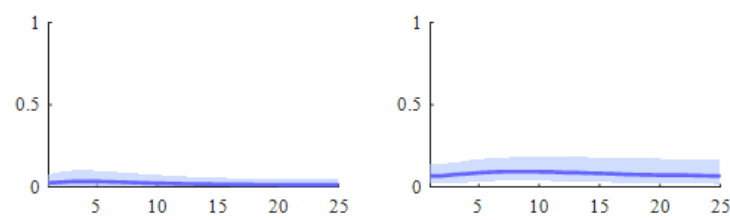

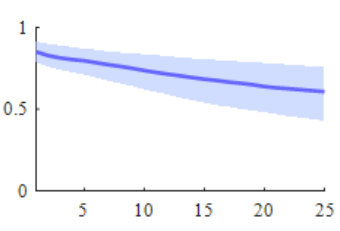

(f) $u_{t}$

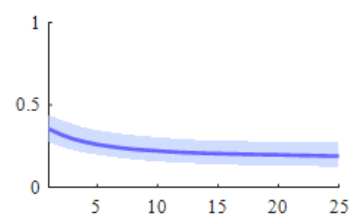

(f) $u_{t}$

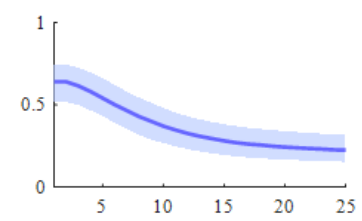
(e) $y_{t}$
(f) $u_{t}$
(a) $i_{t}$
(b) $p_{t}^{+}$
(c) $p_{t}^{-}$
(d) $d e f_{t}$

(e)

Note: The dark line is the median and the shaded area is the $68 \%$ credible set. 


\section{Conclusions}

The issue of whether oil price shocks may be detrimental in terms of economic growth and unemployment has been a subject of recent interest in the academic literature. On the one hand, one can argue that oil price shocks act as supply-side shocks, negatively affecting the potential output and natural rate of unemployment. On the other hand, if a country produces and exports oil, an increase in the price of this commodity may help the trade balance and boost GDP and employment.

In this paper, we analyse the effect on unemployment of oil price shocks for the case of the UK. We find that oil shocks have had an impact on the UK unemployment rate since the beginning of the sample in 2000Q1. We also find that the relationship between oil prices and unemployment, and the contribution of oil price innovations to the variance of unemployment differs somewhat when comparing the periods before and after 2008Q1.

We also account for the possibility of asymmetric effects, i.e. whether the effect of positive oil price innovations on unemployment differs in magnitude from that of negative innovations. According to our results, it seems that although positive oil price movements had a stronger negative effect on employment before the crisis, the post-crisis drops in oil price have contributed to keeping the UK unemployment rate at low levels.

In terms of policy-making, when assessing the potential effect of an oil shock on unemployment dynamics, the authorities need to account for and forecast the sign of shocks. 


\section{References}

Andreopoulos, S. (2009) Oil Matters: Real input prices and U.S. unemployment revisited, The B.E. Journal of Macroeconomics 9, 1-31.

Blanchard, O. and R. Perotti (2002): An empirical characterisation of the dynamic effects of changes in government spending and taxes on output, Quarterly Journal of Economics 117, pp. 1329-1368.

Carruth, A. A, M. A. Hooker and A. J. Oswald (1998): Unemployment equilibria and input prices: Theory and evidence from the United States, Review of Economics and Statistic 80, 621628.

Cuestas, J.C. (2016): The impact of supply shocks on unemployment in Spain, Economics and Business Letters 5, 107-112.

Cunado, J. and F. Perez de Gracia (2003): Do oil price shocks matter? Evidence for some European countries, Energy Economics 25, 137-154.

Dieppe, A., R. Legrand and B. van Roye (2016): The BEAR toolbox, ECB Working Paper Series, no 1934.

Evgenidis, A. (2018): Do all price shocks have the same impact? Evidence from the euro area, Finance Research Letters, forthcoming.

Frias-Pinedo, I., R. Diaz-Vazquez and A. Iglesias-Casal (2017): Oil prices and economic downturns: the case of Spain, Applied Economics 49, 1637-1654.

Gil-Alana, L. A. (2003): Unemployment and real oil prices in Australia: a fractionally cointegrated approach. Applied Economics Letters 10, 201-204.

Gil-Alana, L. A. (2006): UK Unemployment Dynamics: a Fractionally Cointegrated Approach, Economia Internazionale / International Economics, Camera di Commercio di Genova, 59, 33-50.

Gil-Alana, L. A. and G. S. B. Henry (2003): Fractional Integration and the Dynamics of UK Unemployment. Oxford Bulletin of Economics and Statistics, 65, 221-239. 
Hamilton, J. D. (1983): Oil and the macroeconomy since World War II. Journal of Political Economy 91, 228-248.

Hamilton, J. D. (1988): A neoclassical model of unemployment and the business cycle. Journal of Political Economy 96, 593-617.

Jiménez-Rodríguez, R. (2009): Oil Price Shocks and Real GDP Growth: Testing for NonLinearity, The Energy Journal 30, 1-23.

Jiménez-Rodríguez, R. and M. Sánchez (2005): Oil Price Shocks and Real GDP Growth: Empirical Evidence for Some OECD Countries. Applied Economics 37, 201-228.

Katircioglu, S. T., K. Sertoglu, M. Candemir and M. Mercan (2015): Oil price movements and macroeconomic performance: Evidence from twenty-six OECD countries, Renewable and Sustainable Energy Reviews, vol. 44, pp. 257-270.

Litterman, R. (1986): Forecasting with Bayesian Vector Autoregressions - Five years of experience, Journal of Business and Economic Statistics 4, 25-38.

Shapiro, C. and J. E. Stiglitz (1984): Equilibrium unemployment as a worker discipline device. American Economic Review 74, 433-444.

Sims, C. A. (1988): Bayesian skepticism on unit root econometrics, Journal of Economic Dynamics and Control 12, 463-474.

\section{Appendix:}

\section{Descriptive statistics}

\begin{tabular}{|l|l|l|l|l|}
\hline & $y_{t}$ & $p_{t}$ & $i_{t}$ & def \\
\hline Mean & 14.252 & 1.825 & 0.030 & 0.0004 \\
\hline Median & 14.278 & 1.871 & 0.040 & -0.0029 \\
\hline Maximum & 14.360 & 2.120 & 0.060 & 0.1259 \\
\hline
\end{tabular}




\begin{tabular}{|l|l|l|l|l|}
\hline Minimum & 14.100 & 1.412 & 0.005 & -0.1291 \\
\hline Std. Dev & 0.070 & 0.204 & 0.021 & 0.0316 \\
\hline
\end{tabular}

\section{Granger causality tests for oil prices}

\begin{tabular}{|l|l|l|}
\hline Equation & Chi squared statistic & p-value \\
\hline$i_{t}$ & 15.042 & 0.001 \\
\hline$y_{t}$ & 2.236 & 0.326 \\
\hline$d e f_{t}$ & 4.157 & 0.125 \\
\hline$u_{t}$ & 4.88 & 0.087 \\
\hline
\end{tabular}

